\title{
Association of vitamin $D$ deficiency in pregnancy and risk of preterm labor
}

\section{Original Article}

\author{
M. A. M. Ibrahim, Rehab M. Abdel-Rahman, Marwa A. M. A. El-Kateb
}

Department of Obstetrics and Gynecology, Faculty of Medicine, Ain Shams University, Cairo, Egypt.

\begin{abstract}
Introduction: Prematurity represents around $50-75 \%$ of the perinatal mortality causes. It is considered a challenging clinical scenario faced in every day practice. Preterm labor is clinically definedas the beginning of regular uterine contractions accompanying cervical changes before 37 gestational week's completion with or without intact fetal membranes.

Aim of the work: To assess the association between vitamin D status and preterm labor.

Patients and Methods: 80 pregnant study subjects with singleton pregnancy between 20-28 gestational weeks were followed up for any sign or symptom of preterm labor. Study subjects that completed 37 gestational weeks were considered controls, others delivered before 37 gestational weeks were considered cases. A blood sample was collected from cases and controls and was frozen till reaching our target of PTBs then serum 25(OH) VD was assayed by ELISA.

Results: Vitamin D levels were less in the preterm research group in statistically significant fashion $(p$ value $=0.000)$. GA age at delivery was statistically significantly correlated to vitamin D levels in which Pearson correlation $=0.571$ ( $p$ value $=0.000$ ). Vitamin D deficiency was statistically significantly more prevalent in preterm research group ; while vitamin D sufficiency and insufficiency were more prevalent in full term research group in statistically significant manner ( $p$ value $=0.000)$.

Conclusion: A significant association between vitamin D deficiency in pregnancy and occurrence of preterm labor. Future research studies should in addition consider racial, ethnic differences between study subjects recruited in a comparative manner and seasonal variabilities that could affect vitamin D status.
\end{abstract}

Key Words: Preterm birth, preterm labor, vitamin D

Received: 24 October 2018, Accepted: 03 November 2018

Corresponding Author: Marwa A.M.A. El-Kateb, MSc, Department of Obstetrics and Gynecology, Faculty of Medicine, Ain-Shams University, Cairo, Egypt, Tel: 01288236997, Email: marwaelkateb@yahoo.com.

ISSN: 2090-7265, February 2019, Vol.9, No.1

\section{INTRODUCTION}

Preterm labor remains the chief cause of perinatal and neonatal morbidityissues. Since prematurity representsaround $50-75 \%$ of the perinatal mortality causes, it is considered a challenging clinical scenario faced in every day practice. Preterm labor isclinically definedas the beginning of regular uterine contractions accompanying cervical changes before 37 gestational weeks'completionwith or without intact fetal membranes.

Statistical estimation ofpreterm labor rates has ranges around $5-10 \%$ in developed nations toabout $25 \%$ in developing countries. The globalestimated incidence of premature delivery isaround 6 to $11 \% 0^{[1-5]}$.

There is cumulative belief that pretermlabor is not a singular disease, buta syndrome that has a group of possibly independent underlying reasons. Whereas, a great deal of the pathophysiological mechanisms of preterm labor are still vague. There is strong research evidence that intrauterine infection is a common and crucial mechanism leading toearly delivery.Consequently,preterm laborrepresentsa syndrome rather than anexactclinical diagnosis, as causes are variable ${ }^{[6-10]}$.

Vitamin D could be correlated for premature delivery prevention. As 1,25-dihydroxyvitamin $\mathrm{D}$ is proven to decrease bacterial infections by triggering cathelicidin in numerous tissuesinvolving maternal and fetal components of the placenta. Research studies based on laboratory investigations have smartly revealed and displayed linkage between maternal vitamin $\mathrm{D}$ levels by 25 -hydroxyvitamin $\mathrm{D}$ assay and placental antibacterial responsiveness at molecular and cellular levels ${ }^{[1-15]}$.

Vitamin D has gained a growing interest among researchers,clinicians and public community which is well known as a cornerstone hormone in regulation of calcium homeostasis havingadditional wide diverse molecular and cellular impacts influencing various metabolic pathways. Vitamin deficiency is a growing global clinical issue 
affecting the health status of various communities and age groups and of greatinterest the pregnant cases are considered one of the high risk categories to suffer from vitamin D deficiency. Preterm labor in correlation to vitamin D status has been an area of research interest since it affects various pathophysiological pathways that could trigger preterm labor. Vitamin D is well recognized for its non-classical activities such as antioxidant impact, influence on innateimmunological responsiveness and adaptive immunological activities ${ }^{[16-20]}$.

Interestingly, hypovitaminosis $\mathrm{D}$ is correlated toa raised risk for malignancy development, autoimmune disorders, DM and cardiovascular issues, denoting the significance of adequate vitamin D serum levels. In addition, a research-based evidence reveals and displays that vitamin D influences reproductive developments in males and females genital systems ${ }^{[21-25]}$.

Even though various factors for vitamin D status, e.g. seasonality, age, smoking, racial and ethnic based factors have been revealed and displayed in various case-control researchstudies. On the other hand, gestational vitamin D research studies are still deficient and require considerable research efforts to uncover the correlations between vitamin $\mathrm{D}$ status and trending obstetric issues such as preterm labor. In the current research study, the research team is investigating the correlation and linkage between vitamin D deficiency status and the preterm delivery ${ }^{[26-30]}$.

\section{AIM OF THE WORK}

To evaluate and assess vitamin D status and premature labor.

\section{PATIENTS AND METHODS}

Nested case control research study conducted at Ain-Shams University Maternity Hospital and Dar Ismael Maternity Hospital, Health Ministry, was conducted on 80 study subjects in their $2 \mathrm{nd}$ and $3 \mathrm{rd}$ gestational trimesters ${ }^{[20-28]}$ gestational weeks over a period of aroundsix months.

Inclusive research criteria: All women with singleton gestation in their 20-28 gestational weeks were evaluated. Pregnant females with no gross anomalies in their routine antenatal ultrasound were assessed.

Exclusion criteria: Pregnant women with US gross anomalies that may cause preterm labor (either in mother or fetus) ; women with history of preterm labor ; women with documented first trimester aneuploidy scan has documented report from specialized centre and women with incompetent cervix and/or cerclage (in this pregnancy or a previous one)

All study subjects fulfilling inclusion criteria and attending antenatal care clinic were offered to participate in our study. After taking a written consent to participate, a blood sample was collected from the large cohort group and was frozen until later analysis. Follow up for all these women every two weeks for any signs or symptoms of preterm labor were done. Any woman delivered before 37 weeks of gestation was considered a case (preterm) and women who delivered at/or after 37 weeks were considered controls (term). For every case, we searched for a matched control from term women, provided that they shared the same age, parity, BMI and other confounders.Then, we measured 25(OH)VD in the blood samples of cases and matched controls. The DRG $25(\mathrm{OH})$ Vitamin D Total ELISA (Order No. EIA-5396) is an enzyme immunoassay for the quantitative in vitro diagnostic measurement of total $25(\mathrm{OH})$ vitamin D (vitamin D2, D3) in serum of plasma samples (EDTA plasma, heparin plasma and citrate plasma).

Principle of the test: The DRG $25(\mathrm{OH})$ Vitamin D Total ELISA Kit is a solid phase enzyme-linked immunosorbent assay (ELISA) based on the principle of competitive binding.In the first step, samples have to be pretreated in separate vials with denaturation buffer to extract the analyte since most circulating $25(\mathrm{OH})$ Vitamin D is bound to VDBP in vivo. After neutralization, biotinylated $25(\mathrm{OH})$ Vitamin D (enzyme conjugate) and peroxidase-labeled streptavidin- (enzyme complex) are added.After careful mixing, the solution is transferred to the wells of the microtiter plate. Endogenous $25(\mathrm{OH})$ Vitamin D of a patient sample competes with a $25(\mathrm{OH})$ Vitamin D3-biotin conjugate for binding to the VDBG that is immobilized on the plate. Binding of $25(\mathrm{OH})$ Vitamin D-biotin is detected by peroxidase-labeled streptavidin. Incubation is followed by a washing step to remove unbound components. The color intensity is inversely proportional to the concentration of $25(\mathrm{OH}) \mathrm{VD}$ in the sample and was measured photometrically at $450 \mathrm{~nm}$ using ELISA reader (Stat Fax 2100 Microplate Reader) DRG Co., (https://www.drg-diagnostics. de/96- 1-DRG+25-OH+Vitamin+D+Total+ELISA.html).

Included women were then divided into 3 groups according to serum $25(\mathrm{OH}) \mathrm{D}$ levels:

- Deficiency: Vitamin D deficiency (defined as a $25(\mathrm{OH}) \mathrm{D}$ level less than $20 \mathrm{ng} / \mathrm{mL}$ ( $50 \mathrm{nmol} / \mathrm{L})$.

- Insufficiency: Vitamin D insufficiency (defined as a $25(\mathrm{OH}) \mathrm{D}$ concentration of 20 to $30 \mathrm{ng} / \mathrm{mL}$ (50 to 75 $\mathrm{nmol} / \mathrm{L})$.

- Sufficiency: A normal level of vitamin D (defined as a $25(\mathrm{OH}) \mathrm{D}$ concentration greater than $30 \mathrm{ng} / \mathrm{mL}(75 \mathrm{nmol} / \mathrm{L})$

Research Outcomes: Primary research outcome: To evaluate the correlationbetween vitamin D status and preterm labor.

Secondary research outcomes: To evaluate the prevalence of vitamin D deficiency in women with PTL. To measure levels of $25(\mathrm{OH}) \mathrm{VD}$ and divide those into three groups as mentioned before (deficient, insufficient and sufficient). 
Ethical consideration: The information collected out in this study, as regards the conduction, evaluation and documentation of this study, will be designed to ensure that the investigators apply the principles laid down in the current revision of the Declaration of Helsinki for Ethical Medical Research [last updated in Korea, 2008]. This study will be presented to Ethical Committee of Ain-Shams University.

Informed consent: The fundamental principle is respect for the individual.Their right to self-determination and the right to know, understand to make informed decisions, right to privacy, confidentiality. Medical records and information are released to no one without prior written consent.

Statistical Methods: The collected data will be revised, coded, tabulated and introduced to a PC using statistical package for social sciences (IBM SPSS 20.0). Data will be presented and suitable analysis will be done according to the type of data obtained from each parameter.

Descriptive statistics: Mean, standard deviation $( \pm \mathrm{SD})$ and range for parametric numerical data. While,median and interquartile range (IQR)for non-parametric data included frequency and percentage of non-numerical data.

Analytical Statistics: Independent sample t-test will be used to assess the statistical significance of the difference of a parametricvariable between two independent means of two study groups.Chi square test will be used to examine the relationship between two qualitative variables but when the expected count is less than 5 in more than $20 \%$ of the cells; Fisher's Exact Test was used.

P-value level of significance: - $P>0.05$ : Non significant (NS) ; - $P<0.05$ : Significant (S) ; $P<0.01$ : Highly significant (HS)

\section{RESULTS}

Table 1 reveals and displays that age and BMI didn't show statistical significant difference between both research groups ( $p$ values $=0.904$ and 0.58 , consecutively); whereas GA at delivery and vitamin D levels were less in the preterm research group in statistically significant fashion $(p$ value $=0.000)$

Table 2 reveals and displays that there was no statistical significant difference as regards parity,smoking,GDM, preeclampsia $(p$ values $=1.000,1.000,1.000$ and 0.692 , consecutively); however the vaginal deliveries were much less in preterm research group and cesarean section deliveries were more in the same group in statistically significant manner $(p$ values $=0.004)$.

Table 3 reveals and displays that GA age at delivery was statistically significantly correlated to vitamin $D$ levels in which Pearson correlation $=0.571$, $(p$ value $=0.000)$.

Table 4 reveals and displays that Vitamin D deficiency was statistically significantly more prevalent in preterm research group; while vitamin D sufficiency and insufficiency were more prevalent in full term research group in statistically significant manner $(p$ value $=0.000$ )

Table 1: Comparison between group I (Preterm) and group II (Full term) as regard age, BMI, GA of delivery and VD level.

\begin{tabular}{|c|c|c|c|c|c|c|}
\hline & \multicolumn{4}{|c|}{ Group } & \multirow{3}{*}{$\begin{array}{l}\text { Independent } \\
\text { sample } t \text { test }\end{array}$} & \multirow{3}{*}{$P$-value } \\
\hline & \multicolumn{2}{|c|}{ Group I (Preterm) } & \multicolumn{2}{|c|}{ Group II (Full term) } & & \\
\hline & Mean & $\pm \mathrm{SD}$ & Mean & $\pm \mathrm{SD}$ & & \\
\hline Age & 28.47 & 5.56 & 28.32 & 5.48 & 0.121 & 0.904 \\
\hline BMI & 28.94 & 4.00 & 28.48 & 3.55 & 0.544 & 0.588 \\
\hline GA of Delivery & 33.65 & 1.67 & 38.33 & 1.05 & -14.983 & $0.000 * *$ \\
\hline VD & 13.34 & 7.71 & 32.91 & 18.98 & -6.041 & $0.000 * *$ \\
\hline
\end{tabular}


Table 2: Comparison between group I (Preterm) and group II (Full term) as regard parity, smoking status, GDM, preeclampsia and mode of delivery.

\begin{tabular}{|c|c|c|c|c|c|c|c|}
\hline \multirow{3}{*}{ Variables } & & \multicolumn{4}{|c|}{ Group } & \multirow{3}{*}{ Chi square } & \multirow{3}{*}{$P$-value } \\
\hline & & \multicolumn{2}{|c|}{ Group I (Preterm) } & \multicolumn{2}{|c|}{ Group II (Full term) } & & \\
\hline & & No. & $\%$ & No. & $\%$ & & \\
\hline \multirow{4}{*}{ Parity } & 0 & 10 & $25.0 \%$ & 10 & $25.0 \%$ & \multirow{4}{*}{0.000} & \multirow{4}{*}{1.000} \\
\hline & 1 & 10 & $25.0 \%$ & 10 & $25.0 \%$ & & \\
\hline & 2 & 7 & $17.5 \%$ & 7 & $17.5 \%$ & & \\
\hline & $\geq 3$ & 13 & $32.5 \%$ & 13 & $32.5 \%$ & & \\
\hline \multirow{2}{*}{ Smoking } & No & 37 & $92.5 \%$ & 37 & $92.5 \%$ & \multirow{2}{*}{0.000} & \multirow{2}{*}{1.000} \\
\hline & Yes & 3 & $7.5 \%$ & 3 & $7.5 \%$ & & \\
\hline \multirow{2}{*}{ GDM } & No & 37 & $92.5 \%$ & 37 & $92.5 \%$ & \multirow{2}{*}{0.000} & \multirow{2}{*}{1.000} \\
\hline & Yes & 3 & $7.5 \%$ & 3 & $7.5 \%$ & & \\
\hline \multirow{2}{*}{ Preeclampsia } & No & 37 & $92.5 \%$ & 36 & $90.0 \%$ & \multirow{2}{*}{$\begin{array}{c}0.157 \\
\mathrm{FE}(\#)\end{array}$} & \multirow{2}{*}{0.692} \\
\hline & Yes & 3 & $7.5 \%$ & 4 & $10.0 \%$ & & \\
\hline \multirow{2}{*}{ Mode of delivery } & Vaginal & 15 & $37.5 \%$ & 28 & $70.0 \%$ & \multirow[b]{2}{*}{8.498} & \multirow[b]{2}{*}{$0.004 * *$} \\
\hline & Cs & 25 & $62.5 \%$ & 12 & $30.0 \%$ & & \\
\hline
\end{tabular}

Table 3: Correlation between GA at delivery and VD level

\begin{tabular}{lcc}
\hline \multirow{2}{*}{ GA at Delivery } & \multicolumn{2}{c}{ Vit D level } \\
\cline { 2 - 3 } & Pearson Correlation & Sig. (2-tailed) \\
& .571 & $.000^{* *}$ \\
\hline
\end{tabular}

Table 4: Prevalence of Vitamin D deficiency and insufficiency in group I (Preterm) andgroup II (Fullterm).

\begin{tabular}{|c|c|c|c|c|c|c|}
\hline \multirow{3}{*}{ Vit $D$ categories } & \multicolumn{4}{|c|}{ Group } & \multirow{3}{*}{ Chi square test } & \multirow{3}{*}{$P$-value } \\
\hline & \multicolumn{2}{|c|}{ Group I (Preterm) } & \multicolumn{2}{|c|}{ Group II (Full term) } & & \\
\hline & No. & $\%$ & No. & $\%$ & & \\
\hline Sufficiency & 2 & $5.0 \%$ & 19 & $47.5 \%$ & & \\
\hline Insufficiency & 3 & $7.5 \%$ & 12 & $30.0 \%$ & 34.526 & $0.000 * *$ \\
\hline Deficiency & 35 & $87.5 \%$ & 9 & $22.5 \%$ & & \\
\hline
\end{tabular}




\section{DISCUSSION}

Our study was conducted in Ain-Shams University Maternity Hospital and Dar Ismael Maternity Hospital, Health Ministry, on 80 pregnant studysubjects to evaluate the correlation between vitamin D deficiency and preterm labor. The study involved two equal numbered research groups; research group I cases (preterm) and research group II controls (term).

The current research study findings revealed and displayed that age and BMI didnot show statistical significant difference between both research groups ( $p$ values $=0.904$ and 0.58 , consecutively); whereas GA at delivery and vitamin D levels were less in the preterm research group in statistically significant fashion ( $p$ value $=0.000$ ). There was no statistical significant difference as regards parity, smoking,GDM and preeclampsia $(p$ values $=1.000,1.000,1.000$ and 0.692 , consecutively). However, the vaginal deliveries were much less in preterm research group and cesarean section deliveries were more in the same group in statistically significant manner ( $p$ values $=0.004$ ). GA age at delivery was statistically significantly correlated to vitamin D levels in which Pearson correlation $=0.571$ ( $p$ value $=0.000)$. Vitamin D deficiency was statistically significantly more prevalent in preterm research group, while vitamin D sufficiency and insufficiency were more prevalent in full term research group in statistically significant manner $(p$ value $=0.000)$.

A similar previously conducted research study to the current study have revealed and displayed that the serum 25(OH)D concentrations are not statistically different between the preterm labor and the control research groups $(20.9 \pm 8.4$ vs $21.2 \pm 6.7 \mathrm{ng} / \mathrm{mL}, P$ value $=0.91)$. The findings of that study contradict with the current research ; however that could be justified by the fact that there was a small sample size of both cases and controls $^{[31-35]}$.

Another prior research group conducted a research study similar to the current research revealed and displayed that the statistical confounder-adjusted risk of preterm delivery was the highest when 25 - hydroxyvitamin D serum level was below $50 \mathrm{nmol} / \mathrm{L}$ and have fallen as 25-hydroxyvitamin D serum level augmented to around $90 \mathrm{nmol} / \mathrm{L}$, and then have shown plateau ${ }^{[1,3,36,37]}$.

Gestational vitamin D deficiency isl inked with adverse obstetric clinical outcomes. Another research group specifically investigated gestational Vitamin D deficiency and its correlation to the incidence of preterm labor. A total of 3598 eligible pregnant study subjects were recruited. The following results were revealed in which serum $25(\mathrm{OH})$ D serum concentrations was sufficient in 941 study subject, insufficient in 1260 and deficient in 1397. Statistical analysis, in addition, revealed that vitamin $\mathrm{D}$ deficiency was more prevalent in winter than in other seasons. The research group of investigators has shown that underweightis a riskfactor for gestational vitamin
D deficiency. Multivitamin usagedecreased the risk of gestational Vitamin D deficiency. Remarkably, 8.23\% delivered premature neonates have vitamin D deficiency (adjusted $\mathrm{RR}=4.02 ; 95 \% \mathrm{CI}=2.33$ and 6.92 ) and 3.81\% of study subjects have gestational vitamin D insufficiency (adjusted $\mathrm{RR}=2.07$; 95\% CI=1.16, 3.71).Furthermore, $2.59 \%$ delivered early preterm neonates havevitamin D deficiency (adjusted $\mathrm{RR}=2.97 ; 95 \% \mathrm{CI}=1.41,6.24$ ) and $0.49 \%$ has vitamin $\mathrm{D}$ insufficiency (adjusted $\mathrm{RR}=0.54$; 95\% CI: $0.19,1.51)$. The incidence of late preterm labor was $5.64 \%$ among subjects with vitamin D deficiency (adjusted $\mathrm{RR}=3.90 ; 95 \% \mathrm{CI}=2.26,6.72$ ) and $3.32 \%$ among subjects with vitamin D insufficiency (adjusted $\mathrm{RR}=2.09 ; 95 \% \mathrm{CI}: 1.17,3.74)$. It was concluded that pre-gestational BMI, seasonality and multivitamin usage are influent factors for gestational vitamin D status ${ }^{[3,5,7,9]}$.

In a previous research study that recruited 767 cases of spontaneous preterm delivery before 35 gestational weeks, maternal 25 -hydroxyvitamin $\mathrm{D}<30 \mathrm{nmol} / \mathrm{L}$ at 20 gestational weeks was associated with $50 \%$ rise in confounder-adjusted risk in comparison to 25 -hydroxyvitamin $\mathrm{D} \geq 75 \mathrm{nmol} / \mathrm{L}$ among non-white mothers ( $\mathrm{n}=556$ cases), but vitamin $\mathrm{D}$ was not associated among white mothers ( $\mathrm{n}=211$ cases). In a prior research study of twin gestations, the risk of preterm birth $<35$ and $<32$ statistically significantly declined as serum 25-hydroxyvitamin D at 24-28gestational weekswas raised $^{[10,13,15,17]}$.

A prior research meta-analysis of 10 research studies involved 10,098 study subjects found that pregnant women with vitamin $\mathrm{D}$ deficiency (maternal serum 25(OH) D levels $<20 \mathrm{ng} / \mathrm{mL}$ ) experienced a significantly increased risk of preterm labor $[(\mathrm{OR})=1.29$, 95\% (CI): 1.16, 1.45)] $]^{[18,20,23]}$.

Another previous research study similar to the current study supported a protective linkage between maternal vitamin D sufficiency and preterm birth which agreed with epidemiologic research data analysis that provided sufficient justification for a randomized clinical research trial of maternal vitamin $D$ replacement or supplementation to avoid preterm delivery ${ }^{[22,30,32]}$.

A prior research meta-analysis of six randomized controlled research trials and 18 observational research studies revealed and displayed that maternal circulating 25(OH)D deficiency (pooled OR, 1.25; 95\% CI: 1.13-1.38) rather than insufficiency (pooled OR, 1.09; 95\% CI: 0.89-1.35) was correlated and linked with raised risk of preterm laborand vitamin D supplementation alone during pregnancy could reduce the risk of preterm delivery (pooled RR, 0.57; 95\% CI: 0.36-0.91). This was also the case for the spontaneous preterm delivery research subgroup (circulating $25(\mathrm{OH}) \mathrm{D}<50 \mathrm{vs}>50 \mathrm{nmol} / \mathrm{L}$; pooled OR, $1.45 ; 95 \%$ CI: $1.20-1.75)^{[6,10,17,25,37]}$.

Another prior research study that investigated the correlation between the serum level of vitamin D and duration of pregnancy revealed that vitamin D deficiency $(<30 \mathrm{ng} / \mathrm{ml})$ was a frequent and common finding for 
both research groups $(69.6 \%$ of patients in the premature birth group and $72 \%$ in the control group). Patients with premature birth had severe vitamin D deficiency (less than $10 \mathrm{ng} / \mathrm{ml}$ ) more than the control research group (34\% versus $14.2 \%, p$ value $=0.001)$. It was concluded that severe vitamin D deficiency $(<10 \mathrm{ng} / \mathrm{ml})$ could be a risk factor for preterm labor ${ }^{[25,29,35,37]}$.

Furthermore, another research meta-analysis of 24 observational research studies verified the correlation between low vitamin $\mathrm{D}$ serum levels $(<50 \mathrm{nmol} / \mathrm{L})$ and this study aimed to raise the risk of preterm labor (OR $1.58 ; 95 \%$ CI 1.08 to 2.31$)^{[4,8,14,36]}$.

\section{CONCLUSION}

The current study showed a significant association between vitamin $\mathrm{D}$ deficiency in pregnancy and occurrence of preterm labor.A lot of RCTs arerequired to increase the quality of researchevidence about the correlation and linkage betweenlow serumlevels of vitamin D and preterm labor.More clinical research trials are needed to investigate whether vitamin $\mathrm{D}$ test should be a routine laboratoryinvestigation for all pregnant females in antenatal care visits for early diagnosis of vitamin D deficiency to give them treatment to avoid one of the risk factors of pretermlabor. Future research studies should, in addition, consider racial and ethnic differences between study subjects recruited in a comparative manner and seasonal variabilities that could affect vitamin D status. Furthermore, more clinicalresearch trialsare required to reveal whethersupplementation could reduce the occurrence of preterm labor and improve neonatal morbidity and/or mortality issues and what is the suitable dosage.

\section{CONFLICT OF INTEREST}

There are no conflicts of interest.

\section{REFERENCES}

1. Fernandes S. and Chandra S. (2015): A study of risk factors for preterm labour. Int J Reprod Contracept Obstet Gynecol., 4(5): 1306-1312.

2. Beck S, Wojdyla D, Say L, Betran AP, Merialdi M, Requejo JH, Rubens C, Menon R, Van Look PF (2010): The worldwide incidence of preterm birth: a systematic review of maternal mortality and morbidity. Bulletin of the World Health Organization. 88: 31-8.

3. Goldenberg RL, Culhane JF, Iams JD, Romero $\mathrm{R}(2008)$ : Epidemiology and causes of preterm birth. The Lancet. 371: 75-84.

4. Errol RN, Juliian NR and John RG (2007): Current concepts:The control of labour. New J Med, 341; 9:660-666.
5. Lumley J (2003): Defining the problem: the epidemiology of preterm birth. BJOG, PMID: 12763104

6. Sangkom KUS, Lum BP, Prasert CW, Laopai BM (2015): Antenatal lower genital tract infection screening and treatment programs for preventing preterm delivery. Cochrane data base of systematic review (2).

7. Jasovic-Siveska C (2014): Prevention and Prediction of Preterm Birth-Status Quo in the Last 50 Years. ReprodSyst Sex Disord 2014, 3:2.

8. Patel PK, Pitre DS, Bhooker SP (2015): Predictive value of various risk factors for preterm labor. Natl J Community Med. 2015; 6(1): 121-5

9. Palatnik A and Grobman WA (2015): The relationship between first-trimester subchorionic hematoma, cervical length, and preterm birth. Am J Obstet Gynecol. 213(3): 403-407.

10. Cunningham FG, Gant NF and Leveno KJ. (2005): Physiology and biochemistery of preterm labor. Williams obstetrics. New York: McGraw Hill. 22nd edition 176-177.

11. Romero R, ChaiworaPongsa $\mathrm{T}$, Kuivaviem $\mathrm{H}$ and Tromp G (2004): Bacterial vaginosis, the inflammatory response and the risk of preterm birth a role of genetic epidemiology in the prevention of preterm birth. American J. Obstet Gynecol 190:1509-1519.

12. Edward AD and Tan S (2006): Perinatal infections, prematurity and brain injury. Curr.opinpediatr April; 18 (2): 119 -124.

13. Iams JD, Newman RB, Thom EA, Goldenberg RL, Mueller-Heubach E, Moawad A, Sibai BM, Caritis SN, Miodovnik M, Paul RH, Dombrowski MP, Thurnau G and McNellis D (2002): Frequency of uterine contractions and the risk of spontaneous preterm delivery. N Engl J Med; 346 (4):250-55.

14. Manios Y, Moschonis G, Lambrinou CP, Tsoutsoulopoulou K, Binou P, Karachaliou A, Breidenassel C, Gonzalez-Gross M, Kiely M, Cashman KD (2018): A systematic review of vitamin D status in southern European countries. European journal of nutrition. 57(6):2001-36.

15. Luk J, Torrealday S, Neal Perry G, Pal L (2012): Relevance of vitamin D in reproduction. Human reproduction. 27(10):3015-27.

16. Holick MF (2007): Vitamin D deficiency. New England Journal of Medicine (357):266-81.

17. Pilz S, Ma“rz W, Wellnitz B, Seelhorst U, 
Fahrleitner-Pammer A, Dimai HP, Boehm BO and Dobnig H (2008): Association of vitamin $\mathrm{D}$ deficiency with heart failure and sudden cardiac death in a large cross-sectional study of patients referred for coronary angiography. $\mathrm{J}$ ClinEndocrinol and Metabol. 93: 3927-3935.

18. Lerchbaum E and Obermayer-Pietsch B (2012): European Journal Of Endocrinol 166.

19. Basatemur E,Horsfall L, Marston L, Rait G, Sutcliffe A (2017): Trends in the Diagnosis of Vitamin D Deficiency. Pediatrics.; 139(3): e20162748.

20. Man R, Li L, Cheng C, Wong T Y, Lamoureux E and Sabanayagam C (2017): Prevalence and Determinants of Suboptimal Vitamin D Levels in a Multiethnic Asian Population. Nut; doi:10.3390/ nu9030313

21. Ramagopalan SV, Heger A, Berlanga AJ, Maugeri NJ, Lincoln MR, Burrell A, Handunnetthi L, Handel AE, Disanto G, Orton SM, et al. (2010): A chip-seq defined genome-wide map of vitamin $\mathrm{d}$ receptor binding: Associations with disease and evolution. Genome Res., 20: 1352-1360.

22. Boucher BJ, Mannan N, Noonan K, Hales CN, Evans SJ (1995): Glucose intolerance and impairment of insulin secretion in relation to vitamin D deficiency in east london Asians. Diabetologia; 38: 1239-45.

23. Adams JS and Hewison M (2010): Update in vitamin D. J ClinEndocrinolMetab., doi: $10.1210 /$ jc.2009-1773.

24. Eggemoen ÅR, Falk RS, Knutsen KV, Lagerløv P, Sletner L, Birkeland KI, Jenum AK (2016): Vitamin D deficiency and supplementation in pregnancy in a multiethnic population-based cohort. BMC pregnancy and childbirth. 16(1):7.

25. Liu NQ,Kaplan AT,Lagishetty V,Ouyang YB,Ouyang Y,Simmons CF,Equils O,Hewison $M$ (2011): Vitamin $D$ and the regulation of placental inflammation. J Immunol., doi: 10.4049/jimmunol.1003332.

26. Bodnar LM, Platt RW, Simhan HN (2015): Earlypregnancy vitamin $\mathrm{D}$ deficiency and risk of preterm birth subtypes. Obstetrics and gynecology. $125(2): 439$

27. McDonnell SL, Baggerly KA, Baggerly CA, Aliano JL, French CB, Baggerly LL, Ebeling MD, Rittenberg CS, Goodier CG, Niño JF, Wineland RJ (2017): Maternal $25(\mathrm{OH}) \mathrm{D}$ concentrations $\geq$ $40 \mathrm{ng} / \mathrm{mL}$ associated with $60 \%$ lower preterm birth risk among general obstetrical patients at an urban medical center. PloS one. 12(7):e0180483.

28. Bhupornvivat N and Phupong V (2017): Serum 25-hydroxyvitamin $\mathrm{D}$ in pregnant women during preterm labor. Asia Pac J ClinNutr. doi: 10.6133/ apjen.112015.11.

29. Yang L, Shilei P, Wang YZ, Qin A, Huang Y, Sun S (2016): The Correlation Between Serum Vitamin D Deficiency and Preterm Birth. Med Sci Monit, 22: 4401-4405.

30. Akkar OB, Sancakdar E, Karakus S, Yildiz C, Akkar I, Arslan M, Sahin IO, Yenicesu AG, Cetin A (2016): Evaluation of Maternal Serum 25-Hydroxyvitamin D, Paraoxonase 1 Levels, and Neutrophil-to-Lymphocyte Ratio in Spontaneous Preterm Birth. Medical science monitor: international medical journal of experimental and clinical research. 22:1238.

31. Qin LL, Lu FG, Yang SH, Xu HL, Luo BA (2016): Does maternal vitamin D deficiency increase the risk of preterm birth: a meta-analysis of observational studies. Nutrients. 8(5): 301.

32. Wei SQ (2014): Vitamin D and pregnancy outcomes. Curr Opin Obstet Gynecol 2014, 26:438-447.

33. Zhou SS, Tao YH, Huang $\mathrm{K}$, Zhu BB, Tao FB (2017): Vitamin D and risk of preterm birth: Up to date meta-analysis of randomized controlled trials and observational studies. Journal of Obstetrics and Gynaecology Research. 2017; 43(2):247-56.

34. Baczyńska-Strzecha M and Kalinka J (2017): Assessment of correlation between vitamin $\mathrm{D}$ level and prevalence of preterm births in the population of pregnant women in Poland. International journal of occupational medicine and environmental health. 30(6):933-41.

35. Morley R, Carlin JB, Pasco JA, Wark JD (2006): Maternal 25- hydroxyvitamin D and parathyroid hormone concentrations and offspring birth size. Journal of Clinical Endocrinology and Metabolism 2006; 91(3): 906-12.

36. Wei SQ, Qi HP, Luo ZC, Fraser WD (2013): Maternal vitamin $\mathrm{D}$ status and adverse pregnancy outcomes: a systematic review and metaanalysis. Journal of Maternal-fetal and Neonatal Medicine. 26(9):889-99.

37. Triunfo S and Lanzone A (2016): Potential impact of maternal vitamin D status on obstetric well-being. Journal of endocrinological investigation. 39(1):37-44. 